\title{
IMPROVE THE CATALYTIC ACTIVITY OF FEOOH/BENTONITE MATERIAL BY MECHANICAL ACTIVATION
}

\author{
GUANGTAO WEI ${ }^{a}, Z_{\text {ZHONGMIN LI }}^{a}$, LINYE ZHANG ${ }^{a, b, *}$, YUE DENG ${ }^{a}, L U H U A$ SHAO ${ }^{a}$ and ZIHAN LIU ${ }^{a}$ \\ ${ }^{a}$ School of Chemistry and Chemical Engineering, Guangxi University, Nanning, China \\ ${ }^{b}$ Department of Chemical Engineering, University of Waterloo, Waterloo, Canada
}

\begin{abstract}
To improve the catalytic activity of $\mathrm{FeOOH} /$ bentonite material used in Fenton-like process, the activation of FeOOH/bentonite by mechanical activation was studied. The optimum conditions for activation of $\mathrm{FeOOH} /$ bentonite were as follows: filling ratio of grinding medium $30 \%$, " $15 \mathrm{~mL}$ of D06 balls plus $15 \mathrm{~mL}$ of D10 balls" as combination mode of grinding medium, rotation speed of planet carrier $600 \mathrm{rpm}$, milling time $40 \mathrm{~min}$, and powder-to-ball ratio $0.5: 30\left(\mathrm{~g} \cdot \mathrm{mL}^{-1}\right)$. The mechanical activation was an effective method to improve the catalytic activity of $\mathrm{FeOOH} /$ bentonite. Both the lattice distortion and crystal size decrease happened in $\alpha-\mathrm{FeOOH}$ and the change of layer structure of bentonite were contributed to the increase of catalytic activity of activated FeOOH/bentonite.
\end{abstract}

Keyword: Mechanical activation, Bentonite, $\alpha$-FeOOH, Fenton-like, Catalytic activity

\section{INTRODUCTION}

Even through Fenton oxidation is an effective technology to treat the wastewater containing recalcitrant organic pollutants, some drawbacks existing in conventional homogeneous Fenton system have prevented the wide industrialization of Fenton oxidation in wastewater treatment ${ }^{1,2}$. In order to overcome the drawbacks, heterogeneous catalysts used in Fenton system have aroused attention of the researchers. The Fenton reaction catalyzed by heterogeneous catalyst usually belongs to the Fenton-like process. Heterogeneous catalysts, which commonly are environmentally benign and easily separated, have been reported to overcome the drawbacks of conventional homogeneous Fenton ${ }^{3-5}$. Recently, many solid materials used as the heterogeneous catalysts have been prepared to catalyze the Fenton reaction ${ }^{6,7}$. Bentonite, which is a kind of clay, has particular structures and good properties as well as low cost and abundance in world ${ }^{8}$, so it has been used to prepare bentonite-based heterogeneous catalysts which were successfully used in Fenton-like process ${ }^{9-12}$. It has been proved that $\mathrm{FeOOH} /$ bentonite, i.e. $a$-FeOOH (goethite) pillared bentonite, was a high-efficiency catalytic material for the Fenton-like reaction ${ }^{13}$. However, even high activity of $\mathrm{FeOOH} /$ bentonite, the catalytic property of $\mathrm{FeOOH} /$ bentonite might be further improved by the activated method. Mechanical activation, a green technique used for synthesizing or modifying materials in high-energy ball mill, in essence is a method to change the physical and/or chemical property of materials via mechanical energy ${ }^{14-16}$. When the materials was activated in the high-energy ball mill, through the repeated welding and fracturing which happened in the powder particles of material, mechanical activation could increase the specific surface and form the fresh surface areas of the materials, and even destroy the materials' stable crystalline structure ${ }^{17-21}$.

The aim of this study is to explore the mechanical activation of $\mathrm{FeOOH} /$ bentonite material. In our work, the activation of $\mathrm{FeOOH} /$ bentonite by mechanical activation was firstly investigated in detail, and then based on the XRD characterization of material, the mechanism for improvement of catalytic activity by mechanical activation was also discussed preliminarily.

\section{MATERIALS AND METHODS}

Materials and chemical reagents

Bentonite was purchased from Shanghai No.4 Reagent and H.V. Chemical Limited Company, China; All chemicals and reagents used in the study, including $\mathrm{Fe}\left(\mathrm{NO}_{3}\right)_{3}, \mathrm{Na}_{2} \mathrm{CO}_{3}, \mathrm{HNO}_{3} \mathrm{H}_{2} \mathrm{O}_{2}(30 \%)$ and orange II, were of analytical reagent grade.

Preparation and mechanical activation of $\mathrm{FeOOH} /$ Bentonite catalyst

$\mathrm{Na}_{2} \mathrm{CO}_{3}$ powder was slowly added into the solution of $0.2 \mathrm{~mol} \cdot \mathrm{L}^{-1} \mathrm{Fe}\left(\mathrm{NO}_{3}\right)_{3}$ under room temperature, and the molar ratio of added $\mathrm{Na}_{2} \mathrm{CO}_{3}$ to $\mathrm{Fe}\left(\mathrm{NO}_{3}\right)_{3}$ was about $0.325: 1$. The gained solution was stirred for one day and then aged for one day at room temperature. After that, the intercalation solution was added slowly into bentonite dispersion $(5 \%)$ under vigorous stirring until the dosage of $\mathrm{Fe}^{3+}$ to bentonite amount in the dispersion was about $10 \mathrm{mmol} / \mathrm{g}$. After the mixture was stirred for $8 \mathrm{~h}$ and then aged for one day at $60{ }^{\circ} \mathrm{C}$, the mixture was centrifuged, washed several times with deionized water, dried at $105{ }^{\circ} \mathrm{C}$ overnight, and then ground to less than $0.074 \mathrm{~mm}$. The above dried product was named $\mathrm{FeOOH} /$ bentonite. The $\mathrm{FeOOH} /$ bentonite was then subjected to mechanical activation using an ND8 planetary ball mill (Nanjing University Tianzun Electronic Co., Ltd, China). A certain amount of FeOOH/bentonite was added into the milling chamber $(100 \mathrm{~mL})$ with a certain amount of stainless steel milling balls. After mechanical activation for a certain period of time, the materials were removed from the milling chamber, and then the activated $\mathrm{FeOOH} /$ bentonite was obtained.

Methods of measurement and characterization

The degradation of orange II catalyzed by activated catalyst in the Fenton-like process was carried out in a water-bathing constant temperature vibrator with an agitation speed of $200 \mathrm{rpm}$. The reaction conditions were as follows: initial concentration of orange II $40 \mathrm{mg} \cdot \mathrm{L}^{-1}$, temperature $30^{\circ} \mathrm{C}, \mathrm{pH}$ of solution 3.0, dosage of $\mathrm{H}_{2} \mathrm{O}_{2} 19.6 \mathrm{mmol} \cdot \mathrm{L}^{-1}$, and dosage of catalyst $0.2 \mathrm{~g} \cdot \mathrm{L}^{-1}$. The solution samples were taken at reaction time of $2 \mathrm{~h}$, and then centrifuged to separate catalyst from the suspension at $3500 \mathrm{rpm}$ for 10 minutes. The remaining orange II in sample solution was determined using a VIS-722 visible spectrophotometer (Shanghai Yoke Instrument Co., Ltd., China) at 485 $\mathrm{nm}$ which is the maximum absorbance wavelength of orange II solution. The catalytic property of catalyst was evaluated by the removal ratio of orange II which was calculated with the following formula:

$$
\eta=\frac{C_{0}-C_{\mathrm{t}}}{C_{0}} \times 100 \%
$$

where $C_{\mathrm{t}}$ and $C_{0}$ represent the time-dependent concentration and the initial concentration, respectively. After the degradation of orange II, the content of total iron ions $\left(C_{\mathrm{tol}}, \mathrm{mg} \cdot \mathrm{L}^{-1}\right)$ and the content of ferrous iron ions $\left(C_{\mathrm{Fe}}{ }^{2+}\right.$, $\left.\mathrm{mg} \cdot \mathrm{L}^{-1}\right)$ in the solution were measured by the method of o-phenanthroline spectrophotometry.

XRD patterns of catalyst were measured with a D8 ADVANCE X-ray diffractometer (Bruker, Germany) equipped with $\mathrm{Cu}$ and $\mathrm{Ka}$ radiation at $40 \mathrm{kV}$ and $40 \mathrm{~mA}$, and the recorded $2 \theta$ was in the range of $5 \sim 80^{\circ}$.

\section{RESULTS AND DISCUSSION}

Effect of filling ratio of grinding medium on $\mathrm{FeOOH} / \mathrm{bentonite}$ catalytic activity

$0.5 \mathrm{~g}$ of $\mathrm{FeOOH} /$ bentonite was placed into the milling chamber, and the following conditions were used for mechanical activation: stainless steel milling balls with a diameter of $10 \mathrm{~mm}$ as grinding medium, rotation speed of planet carrier $600 \mathrm{rpm}$, and milling time $60 \mathrm{~min}$. The effect of filling ratio of grinding medium on the catalytic activity of activated $\mathrm{FeOOH} /$ bentonite is shown in Fig. 1. 


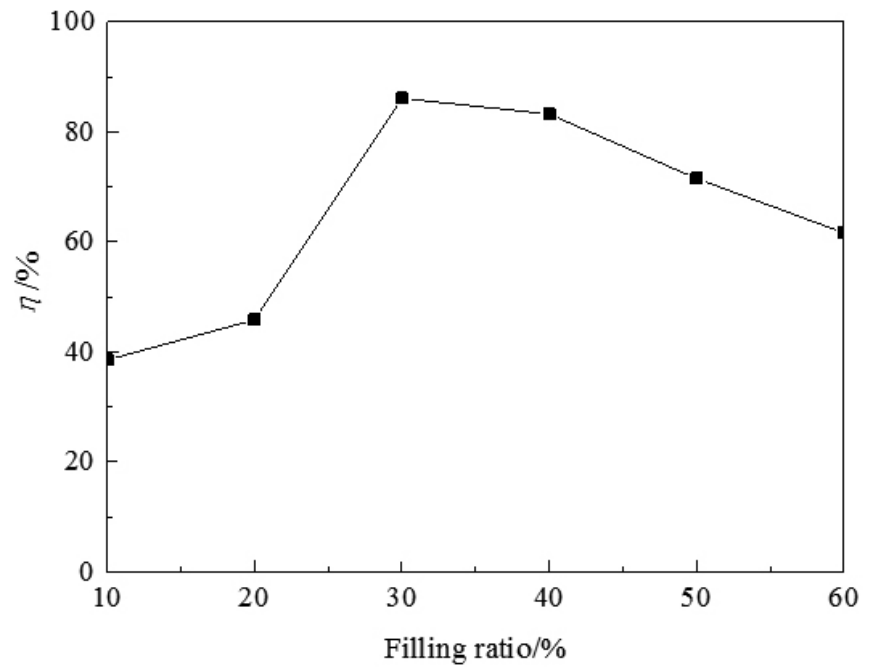

Fig 1. Effect of filling ratio of grinding medium on the removal ratio of orange II.

As shown in Fig. 1, when the filling ratio of grinding medium was less than $30 \%$, the catalytic activity increased with the filling ratio increase, and the catalytic activity reached its maximum at the filling ratio of $30 \%$, with the corresponding removal ratio of orange II of $86.1 \%$. When the filling ratio was over $30 \%$, the catalytic activity declined with the further increase of filling ratio. Therefore, the filling ratio of $30 \%$ was used for the mechanical activation in all subsequent experiments. When the filling ratio was too low, the contact between stainless steel milling balls and $\mathrm{FeOOH} /$ bentonite in the milling chamber was not enough, so the collision and friction between stainless stee milling balls and $\mathrm{FeOOH} /$ bentonite was not sufficient. With the increase of filling ratio, the collision frequency between stainless steel milling balls and $\mathrm{FeOOH} /$ bentonite was increased, which could make the mechanical activation effect on the $\mathrm{FeOOH} /$ bentonite increase quickly. However, when the filling ratio of grinding medium was too high, the void in the milling chamber became small, which formed a "dead zone" for the mechanical activation. In the "dead zone", the grinding medium and the material only could move slowly. And, furthermore, the free path of stainless steel milling balls in the "dead zone" was shortened. Hence, the mechanical activation effect was greatly weakened as a result of the high filling ratio of grinding medium.

Effect of combination mode of grinding medium on $\mathrm{FeOOH} /$ bentonite catalytic activity

Two kinds of stainless steel milling balls with diameters of $6 \mathrm{~mm}$ and 10 $\mathrm{mm}$ were used to study the effect of combination mode of milling balls on the catalytic activity of activated $\mathrm{FeOOH} /$ bentonite. The stainless steel milling balls with diameter of $6 \mathrm{~mm}$ and $10 \mathrm{~mm}$ were designed as D06 balls, and D10 balls, respectively. The conditions of mechanical activation were as follows: mass of $\mathrm{FeOOH} /$ bentonite $0.5 \mathrm{~g}$, filling ratio of grinding medium $30 \%$, rotation speed of planet carrier $600 \mathrm{rpm}$, and milling time $60 \mathrm{~min}$. The removal ratios of orange II catalyzed by the $\mathrm{FeOOH} / \mathrm{bentonite}$ catalysts which were activated under different combination modes of milling balls are listed in Fig.2.

As shown in Fig. 2, the catalytic activity of $\mathrm{FeOOH} /$ bentonite catalyst activated under the combination mode of "D06,15\%+D10,15\%", i.e, $15 \mathrm{~mL}$ of D06 balls plus $15 \mathrm{~mL}$ of D10 balls, was the highest. During the activation of $\mathrm{FeOOH} /$ bentonite, the voids between stainless steel milling balls were inevitably generated in the cylindrical milling chamber. However, when the stainless steel milling balls with different diameters were selected as the grinding medium, the bigger balls could increase the impact force and the shear force, both of which came from the grinding between balls. Furthermore, the smaller balls could easily fill the voids between the bigger balls, so that the contact surface between stainless steel milling balls and $\mathrm{FeOOH} /$ bentonite material increased during the process of mechanical activation, and the friction between stainless steel milling balls and $\mathrm{FeOOH} /$ bentonite material also increased. The combination mode of "D06,15\%+D10,15\%" was chosen as the optimum condition in all subsequent mechanical activation experiments.

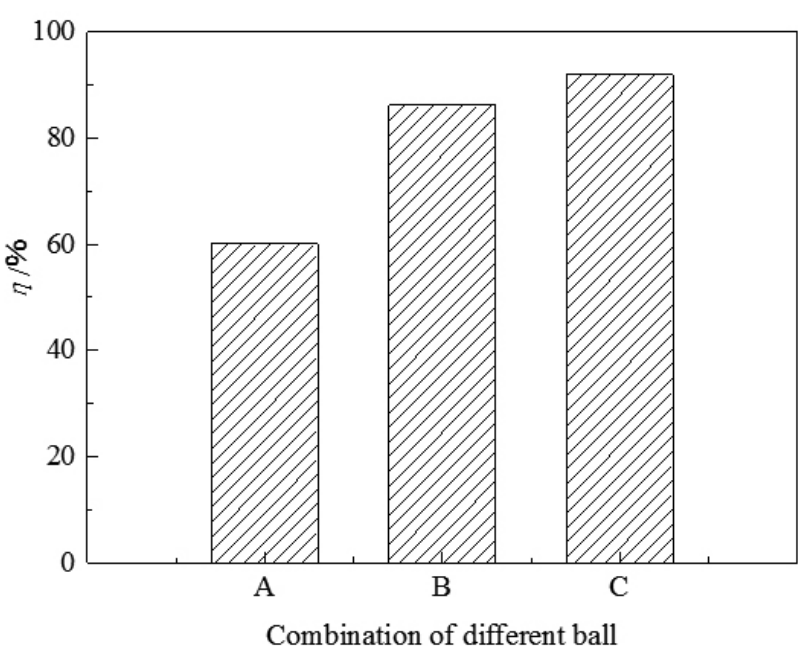

Fig 2. Effect of combination mode of different balls on the removal ratio of orange II: (A) D06,30\%; (B) D10,30\%; (C) D06,15\%+D10,15\%

Effect of rotation speed of planet carrier on $\mathrm{FeOOH} /$ bentonite catalytic activity

To analyze the effect of rotation speed of planet carrier on the catalytic activity of $\mathrm{FeOOH} /$ bentonite, $\mathrm{FeOOH} /$ bentonite was activated at different rotation speed under the condition: mass of $\mathrm{FeOOH} / \mathrm{bentonite} 0.5 \mathrm{~g}$, combination mode of "D06,15\%+D10,15\%", filling ratio $30 \%$, and milling time $60 \mathrm{~min}$. The effect of rotation speed of planet carrier on the catalytic activity of $\mathrm{FeOOH} /$ bentonite is shown in Fig. 3.

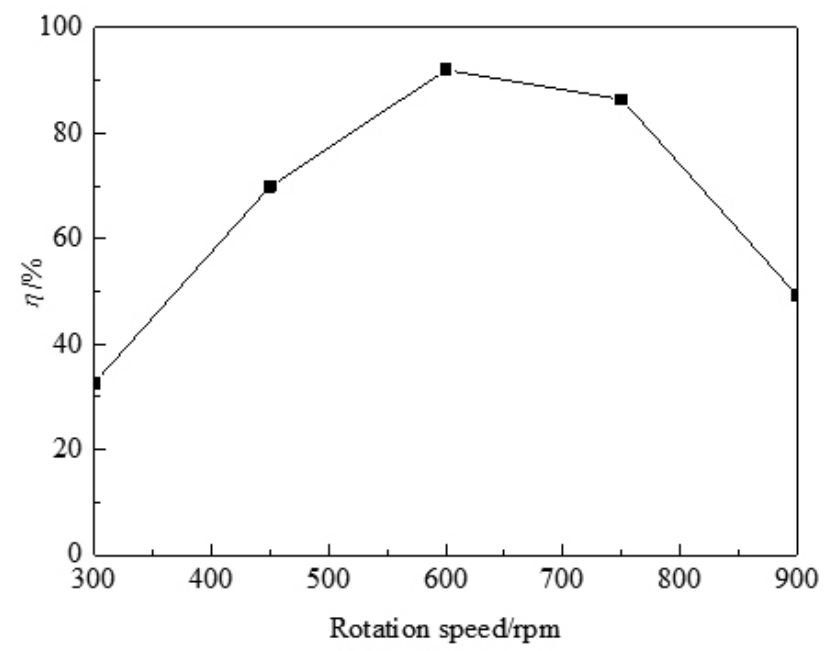

Fig 3. Effect of rotation speed of planet carrier on the removal ratio of orange II.

With the increase of rotation speed of planet carrier, the removal ratio of orange II increased until the rotation speed was $600 \mathrm{rpm}$, and the removal ratio reached its maximum at $600 \mathrm{rpm}$. The results indicated that the activated $\mathrm{FeOOH} /$ bentonite reached its highest activity at the rotation speed of 600 $\mathrm{rpm}$. At low rotation speed, the movement of stainless steel milling balls in the milling chamber was in a motion state of cascading. In this motion state, the stress on the $\mathrm{FeOOH} /$ bentonite would be mostly the compression and shear stress between milling balls or milling balls and milling chamber wall. With the increase of rotation speed, even though no detachment of balls from the wall or the other balls occurred, the compression and shear stress on the $\mathrm{FeOOH} /$ bentonite increased quickly with the rotation speed increase, which resulted in the increase of catalytic activity of $\mathrm{FeOOH} /$ bentonite. However, when the rotation speed was $600 \mathrm{rpm}$, the movement of milling balls might shift from the cascading motion into the cataracting motion, in which a fraction 
of the milling balls detached from the grinding chamber wall and followed a parabola trajectory in flight before impacting into the bulk of balls. Besides the compression and shear stress, as existed in the cascading motion, the impact stress on the $\mathrm{FeOOH} /$ bentonite from dropping down balls also occurred in the cataracting motion. Hence, the catalytic activity of $\mathrm{FeOOH} /$ bentonite reached its maximum at the rotation speed of $600 \mathrm{rpm}$. A slight drop of catalytic activity with the further increase of rotation speed which was over $600 \mathrm{rpm}$ might be because that part of milling balls were in the centrifugation motion, in which the centrifuged milling balls aligned on the chamber wall and followed its rotation with almost no relative velocity, which made the stress on the $\mathrm{FeOOH} /$ bentonite decline slightly.

Effect of milling time on $\mathrm{FeOOH} / \mathrm{bentonite}$ catalytic activity

The effect of milling time on the catalytic activity of $\mathrm{FeOOH} /$ bentonite was investigated, and the parameters used for mechanical activation were as follows: mass of $\mathrm{FeOOH} /$ bentonite $0.5 \mathrm{~g}$, combination mode of "D06,15\%+D10,15\%", filling ratio $30 \%$, and rotation speed of planet carrier $600 \mathrm{rpm}$. The result is shown in Fig. 4.

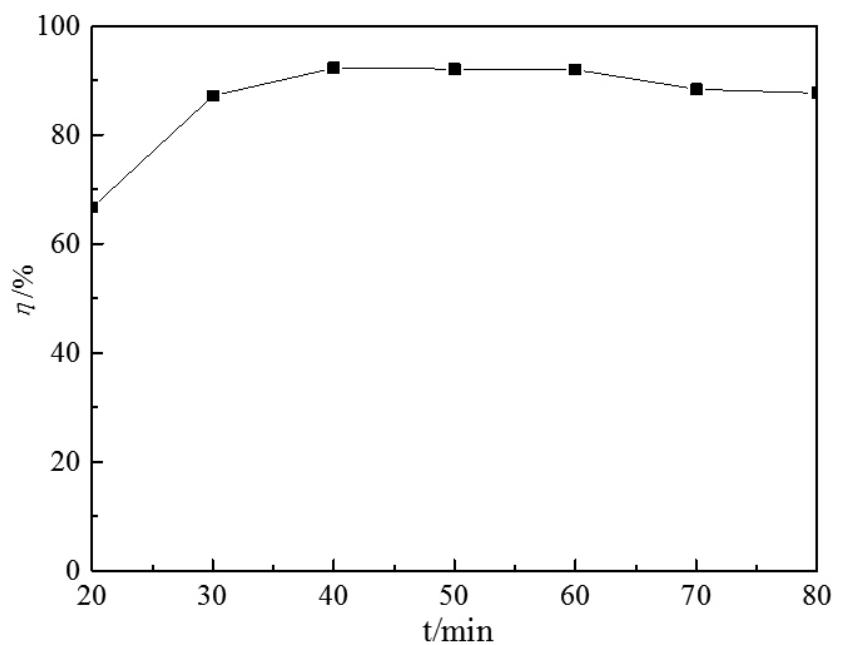

Fig 4. Effect of milling time on the removal ratio of orange II

The catalytic activity of $\mathrm{FeOOH} /$ bentonite first increased with the increase of milling time from 20 to $40 \mathrm{~min}$, and then remained almost stable when milling time was over $40 \mathrm{~min}$. The reason for such a result was that with the increase of milling time, the $\mathrm{FeOOH} /$ bentonite in the milling chamber was fully activated. The milling time of $40 \mathrm{~min}$ was chosen as the optimum condition in all subsequent mechanical activation experiments.

Effect of powder-to-ball ratio on $\mathrm{FeOOH} /$ bentonite catalytic activity

To investigate the influence of powder-to-ball ratio in the process of mechanical activation on the catalytic activity of $\mathrm{FeOOH} /$ bentonite, $\mathrm{FeOOH} /$ bentonite material was activated at different powder-to-ball ratio which was defined as the ratio of mass of activated powder to packing volume of milling balls $\left(R, \mathrm{~g} \cdot \mathrm{mL}^{-1}\right)$. And the other parameters used for mechanical activation were as follows: combination mode of "D $06,15 \%+\mathrm{D} 10,15 \%$ ", filling ratio $30 \%$, rotation speed of planet carrier $600 \mathrm{rpm}$, and milling time $60 \mathrm{~min}$. Moreover, in order to identify the enhancement effect on catalytic activity by mechanical activation, a comparative experiment of orange II degradation in Fenton-like process catalyzed by $\mathrm{FeOOH} /$ bentonite, which was without the treatment of mechanical activation, was also carried out. The results are listed in Table 1.

Table 1. Removal ratios of orange II catalyzed by different catalysts.

\begin{tabular}{|c|c|c|}
\hline Catalysts & $R_{\mathrm{ptb}}\left(\mathrm{g} \cdot \mathrm{mL}^{-1}\right)$ & $\eta(\%)$ \\
\hline Activated $\mathrm{FeOOH} /$ bentonite & $0.25: 30$ & 75.5 \\
\hline Activated $\mathrm{FeOOH} /$ bentonite & $0.5: 30$ & 92.3 \\
\hline Activated $\mathrm{FeOOH} /$ bentonite & $0.75: 30$ & 80.7 \\
\hline Activated $\mathrm{FeOOH} /$ bentonite & $1.0: 30$ & 78.5 \\
\hline FeOOH/bentonite & N/A & 26.3 \\
\hline
\end{tabular}

As shown in Table 1, with the increase of $R_{\mathrm{ptb}}$, i.e. with the increase of mass of $\mathrm{FeOOH} /$ bentonite added into the milling chamber, the catalytic activity of $\mathrm{FeOOH} /$ bentonite increased quickly until the $R_{\text {th }}$ was $0.5: 30\left(\mathrm{~g} \cdot \mathrm{mL}^{-1}\right)$, and then the catalytic activity decreased with the further increase of $R$. With the increase of $R_{\mathrm{ptb}}$, the increase of $\mathrm{FeOOH} /$ bentonite mass increased the contact between $\mathrm{FeOOH} /$ bentonite and milling balls. The stress effect on $\mathrm{FeOOH} /$ bentonite also changed more sufficient for enough collision between powder and milling balls, so that the mechanical energy from the milling balls could easily transform into the internal energy of $\mathrm{FeOOH} /$ bentonite powder. However, when the value of $R_{\mathrm{ptb}}$ was over $0.5: 30\left(\mathrm{~g} \cdot \mathrm{mL}^{-1}\right)$, the dosage of $\mathrm{FeOOH} /$ bentonite was too excessive in the milling chamber, and the powder accumulation formed in the gaps between milling balls or milling balls and milling chamber wall. Therefore, partial $\mathrm{FeOOH} /$ bentonite could not get enough mechanical stress, which produced a negative effect on the activation of $\mathrm{FeOOH} / \mathrm{bentonite}$. Hence, the $R_{\mathrm{ptb}}$ of $0.5: 30\left(\mathrm{~g} \cdot \mathrm{mL}^{-1}\right)$ was chosen as the optimum condition for the mechanical activation of $\mathrm{FeOOH} /$ bentonite. Moreover, as shown in Table 1, compared with the high removal ratios of orange II catalyzed by the activated $\mathrm{FeOOH} /$ bentonites, the removal ratio catalyzed by the $\mathrm{FeOOH} /$ bentonite was only reached $26.3 \%$, indicating that the mechanical activation was an effective method to improve the catalytic activity of $\mathrm{FeOOH} /$ bentonite.

Catalyst characterization and mechanism of catalytic activity improvement

The X-ray diffraction patterns of $\mathrm{FeOOH} /$ bentonite and activated $\mathrm{FeOOH} /$ bentonite are shown in Fig. 5. As shown in Fig. 5, FeOOH/bentonite revealed the presence of signals in $2 \theta$ positions corresponding to $21.22^{\circ}, 33.24^{\circ}, 39.98^{\circ}$ and $53.23^{\circ}$, which were characteristic peaks of $\alpha-\mathrm{FeOOH}$ (JCPDS: 29-0713), indicating that the iron phase immobilized on bentonite was mainly in form of $\alpha$-FeOOH. Likewise, the pattern of activated $\mathrm{FeOOH} /$ entonite exhibited diffraction peaks at $2 \theta 21.22^{\circ}, 33.24^{\circ}, 39.98^{\circ}$ and $53.23^{\circ}$. However, compared to the characteristic peaks of $\alpha$ - $\mathrm{FeOOH}$ on $\mathrm{FeOOH} /$ bentonite, the broadening of diffraction peaks of $\alpha-\mathrm{FeOOH}$ was observed from the pattern of activated $\mathrm{FeOOH} /$ bentonite, indicating that under mechanical activation, lattice distortion and crystal size decrease might happen in $\alpha-\mathrm{FeOOH}$, which was immobilized on bentonite. Moreover, as shown in Fig. 5, compared to FeOOH/ bentonite, the layer structure of bentonite in the activated $\mathrm{FeOOH} /$ bentonite was destroyed in a certain degree after mechanical activation, which could make the adsorption ability of activated material increase. Hence, under the action of mechanical activation, the microscopic changes in activated $\mathrm{FeOOH} /$ bentonite, including the lattice distortion and crystal size decrease happened in $\alpha-\mathrm{FeOOH}$, and the change of layer structure of bentonite, were contributed to the increase of catalytic activity of activated material.

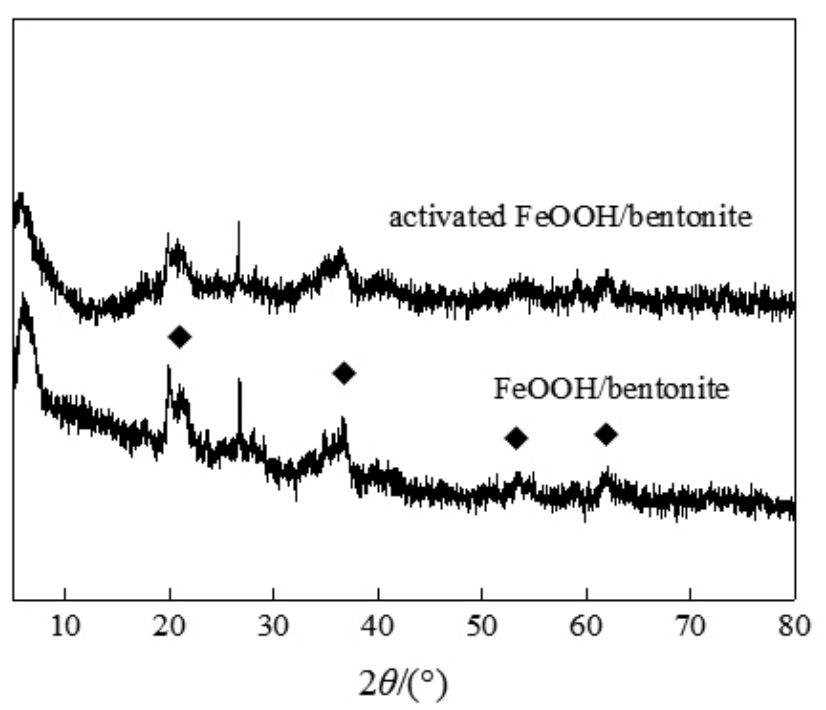

Fig 5. XRD spectra of samples

\section{CONCLUSIONS}

The optimum conditions for activation of $\mathrm{FeOOH} /$ bentonite by mechanical activation were as follows: filling ratio of grinding medium $30 \%$, " $15 \mathrm{~mL}$ of D06 balls plus $15 \mathrm{~mL}$ of D10 balls" as combination mode of grinding medium, 
rotation speed of planet carrier $600 \mathrm{rpm}$, milling time $40 \mathrm{~min}$, and powderto-ball ratio $0.5: 30\left(\mathrm{~g} \cdot \mathrm{mL}^{-1}\right)$. The mechanical activation was an effective method to improve the catalytic activity of $\mathrm{FeOOH} /$ bentonite. Both the lattice distortion and crystal size decrease happened in $\alpha-\mathrm{FeOOH}$ and the change of layer structure of bentonite were contributed to the increase of catalytic activity of activated $\mathrm{FeOOH} /$ bentonite.

\section{ACKNOWLEDGEMENTS}

The work was supported by National Natural Science Foundation of China (21667004) and Guangxi Science Foundation Funded Project (2015GXNSFCA139017, 2015GXNSFBA139031).

\section{REFERENCES}

1.- C. Feng, H.H. Sun, S.Q. Li, M.K. Camarillo, W.T. Stringfellow, Y.Y. Liang, Water Sci. Technol. 71, 1884-1892, (2015).

2.- M.D. Richmond, Water Environ. Res. 87, 650-655, (2015).

3.- L.Z. Zhang, H.H. Zeng, Y.M. Zeng, Z.H. Zhang, X.F. Zhao, J. Mol. Catal. A: Chem. 392, 202-207, (2014).

4.- A. Babuponnusami, K. Muthukumar, J. Environ. Chem. Eng. 2(1), $557-$ $572,(2014)$.

5.- S.H. Hu, Y.G. Wu, H.R. Yao, C. Lu, C.J. Zhang, Water Sci. Technol. 73(1), 153-160, (2016).

6.- A. Cihanoğlu, G. Gündüz, M. Dükkancı, Appl. Catal. B: Environ. 165, 687-699, (2015).

7.- L.H. Shao, G.T. Wei, Y.Z. Wang, Z.M. Li, L.Y. Zhang, S.K. Zhao, M. Zhou, Environ. Sci. Pollut. R. (2016), DOI:10.1007/s11356-016-6691-4.
8.- G.T. Wei, C.Y. Fan, L.Y. Zhang, R.C. Ye, T.Y. Wei, Z.F. Tong, Catal. Commun. 17, 184-188, (2012).

9.- S.T. Khankhasaeva, D.V. Dambueva, E.T. Dashinamzhilova, A. Gil, M.A. Vicente, M.N. Timofeeva, J. Hazard. Mater. 293, 21-29, (2015).

10.- L.Y. Zhang, S.Y. Cai, J.H. Mo, G.T. Wei, Z.M. Li, R.C. Ye, X.M. Xie, Mater. Manuf. Process. 30(3), 279-284, (2015).

11.- Q.Q. Chen, P.X. Wu, Y.Y. Li, N.W. Zhu, Z. Dang, J. Hazard. Mater. 168(23), 901-908, (2009)

12.- L.Y. Zhang, S.Y. Cai, K. Huang, Z.M. Li, G.T. Wei, X.H. Li, J.H. Mo, Y.C. Liang, Desalin. Water Treat. 51(40-42), 7815-7824, (2013).

13.- J.X. Chen, L.Z. Zhu, Sep. Purif. Technol. 67(3), 282-288, (2009).

14.- M.A. Khaghani-Dehaghani, R. Ebrahimi-Kahrizsangi, N. Setoudeh, B. Nasiri-Tabrizi, Int. J. Refract. Met. H. 29(2), 244-249, (2011).

15.- K. G. Prashanth, Mater. Manuf. Process. 25(9), 974-977, (2010).

16.- A. Terzića, L. Pezo, L. Andrić, M. Arsenović, Compos Part B: Eng. 79, 660-666, (2015).

17.- S.F. Tikhov, V.A. Sadykov, K.R. Valeev, A.N. Salanov, S.V. Cherepanova, Y.N. Bespalko, V.E. Ramanenkau, Y.Y. Piatsiushyk, S.V. Dimov, Cataly. Today 246, 232-238, (2015).

18.- J. Choi, Y. Han, D. Kim, S. Park, J. Park, J. Park, H. Kim, Mater. Trans. 55(12), 1895-1899, (2014).

19.- M. Razavi, R. Ghaderi, M.R. Rahimipour, M.O. Shabni, Mater. Manuf. Process. 27(12), 1310-1314, (2012).

20.- A. Allahverdi, M. Mahinroosta, Powder Technol. 245(8), 182-188, (2013).

21.- V. Shojaei, M. Schaffie, A. Mohebbi, M. Ranjbar, Mater. Manuf. Process. 29(10), 1284-1288, (2014). 